\title{
CULTIVAR, COMPARTILHAR E COMER: FRAGMENTOS DA CULTURA ALIMENTAR QUILOMBOLA DA BOCAINA (MATO GROSSO)
}

\author{
CULTIVATING, SHARING AND EATING: FRAGMENTS OF THE QUILOMBOLA \\ FOOD CULTURE OF BOCAINA (MATO GROSSO)
}

\author{
Flávio Bezerra BARROS
}

${ }^{1}$ Instituto Amazônico de Agriculturas Familiares, Universidade Federal do Pará, Belém, Pará, Brasil. E-mail: flaviobb@ufpa.br

Este ensaio fotográfico tem o objetivo de apresentar aspectos da cultura alimentar ${ }^{1}$ das comunidades quilombolas Pé de Galinha e Sete Barreiros, ambas localizadas no município de Porto Estrela, Mato Grosso. As famílias que vivem nestas comunidades são oriundas do território quilombola da Bocaina, as quais, na década de 1970, foram expulsas por fazendeiros. Desde este processo violento e ameaçador, que resultou na expropriação da terra, estas famílias vivem esparramadas ${ }^{2}$ por diversos municípios mato-grossenses e outros estados brasileiros. Com a perda da terra, os grupos familiares vivem acampados em condições adversas, não podendo reproduzir com plenitude, suas festas de santo, seus costumes, enfim, seus modos de viver, uma vez que o território lhes foi tomado.

As narrativas orais dos sujeitos desvelam todo o tipo de horror, violências física e simbólica, coações e até mortes enfrentados no tempo do saque. As consequências da expiação são sentidas até o presente, uma vez que não há terra para botar roças (apenas para citar um exemplo), realidade que afeta fortemente a soberania e segurança alimentar dessas famílias. Na Bocaina ficaram as memórias de uma vida comunitária, farta e feliz. Os quilombolas contam sobre a abundância de água, caça, pescado, terras férteis para produzir o alimento cotidiano. A Bocaina era território igualmente dos cemitérios onde eram enterrados seus ancestrais e das festas em que se celebravam os santos católicos, a vida e a dádiva da natureza, elementos demarcadores fundamentais da identidade cultural desse povo.

Com efeito, nossos estudos, por meio do projeto intitulado "Comida de quilombo no Brasil: saberes, práticas alimentares e experiências em contextos do Sul, Centro-Oeste e Norte", financiado pelo CNPq/MCTIC, através do edital SAN No 016/2016, vêm registrando e descrevendo a cultura alimentar desse grupo social a partir de suas sabedorias e práticas alimentares, memórias culinárias e suas estratégias de reprodução em condições difíceis de vida. Desde 2013 mantemos interlocução com o grupo, desenvolvendo pesquisa e acompanhando a trajetória de luta da comunidade, bem como organizando ações de capacitação. Desse processo, uma dissertação de mestrado foi concluída ("Fomos despejados aquil!": conflitos socioambientais, territorialidades e conhecimentos tradicionais dos quilombolas da Bocaina, Província Serrana, Mato Grosso -Brasil, de autoria de Thaís Aparecida Coelhos dos Santos), junto ao Programa de Pós-Graduação em Ciências Ambientais da Unemat. Uma segunda está em fase de conclusão (até agosto de 2020), com a temática das memórias e saberes da alimentação, de autoria de Renata Kelly Costa de Vilhena, via o Programa de Pós-Graduação em Agriculturas Amazônicas da UFPA. Em abril-maio de 2018, por meio do projeto de pesquisa já referenciado, realizei uma oficina de práticas e saberes alimentares, com vistas a estimular a troca de sementes, a aprendizagem acerca das histórias das variedades de produtos da agrobiodiversidade, de receitas, modos de fazer utensílios e cantigas e ladainhas. Nesta dinâmica foi trabalhada uma sessão de confecção de um utensílio muito utilizado em tempos passados, como a apá, hoje produzida por poucos moradores (os mais idosos). Em paralelo fora dinamizada uma oficina sobre a elaboração do prestigiado biscoito de milho tradicional, iguaria muito apreciada na comunidade, sobretudo na época das festas

\footnotetext{
${ }^{1}$ Este conceito compreende o conjunto de práticas, conhecimentos e significados que os grupos sociais atribuem ao ato de comer, o qual transcende o aspecto biológico, mas se reveste de elementos simbólicos e culturais, como bem discutem autores como Da Matta (1986), Maciel (2005) e Menasche (2015).

${ }^{2} \mathrm{O}$ termo local esparramado é constantemente mobilizado nas narrativas locais e se refere ao processo de expulsão das famílias da Bocaina, quando as mesmas tiveram que se espalhar por diferentes lugares para sobreviver.
} 
juninas. Tal intento se sustentou na metodologia da pesquisa-ação (THIOLLENT, 2005). A antropologia visual (ECKERT; ROCHA, 2008) também assume lugar de destaque em nossos estudos, como forma de contar, através do recurso imagético, a cultura da comunidade, para além do texto de cunho etnográfico.

As famílias lutam até o presente, junto aos órgãos do Estado brasileiro, para que o território seja retomado e nossas pesquisas têm contribuído de alguma maneira neste processo pelo reconhecimento do direito à terra tradicionalmente ocupada. Em ambas as comunidades onde vivem atualmente, as famílias tentam reproduzir as roças em seus minúsculos terrenos (os quintais), plantando variedades que cultivam desde os tempos da Bocaina, como cana-de-açúcar, mandioca, milho, banana e hortaliças. Tais rocinhas, como dizem, são apenas para as despesas, se referindo ao consumo familiar. A dinâmica dos vizinhos se ajudarem mutuamente na feitura dos canteiros e "rocinhas" ainda se faz presente, bem como a troca de sementes; contudo, as condições não são apropriadas: falta terra, as variedades estão se perdendo, poucos jovens se interessam pela atividade agrícola. Em algumas famílias que visitei fora do município de Porto Estrela, registrei a conservação de sementes crioulas, cuja justificativa se assenta na ideia de plantá-las quando o território for retomado. É o caso de Dona Rosa, que guarda em sua casa, em garrafas-pet, várias sementes, reproduzindo-as em seu pequeno quintal e até plantando em quintais de vizinhos na cidade de Barra do Bugres/MT, numa luta incessante pela preservação desse patrimônio agrobiodiverso que, segundo ela, é a própria história viva do seu povo, dos seus ancestrais.

As festas de santo também continuam sendo organizadas, como as de São Pedro e São João, na época de junho, mas, como dizem os quilombolas, não têm a mesma graça, pois as condições são inadequadas, uma vez que estão fora da Bocaina, ou seja, esparramados. Há dificuldade de reunir as pessoas, que vivem longe umas das outras; os produtos e artefatos para se preparar as comidas tradicionais e manifestações culturais são difíceis de obter (milho crioulo, panelas de barro, temperos, roupas das danças, como siriri, dentre outros).

Nesta iconografia compartilho imagens que traduzem as práticas alimentares e saberes do povo da Bocaina enquanto estratégia de resistência em face às adversidades enfrentadas há quase 5 décadas de perda de seu território sagrado. O ensaio é ao mesmo tempo uma denúncia ao Estado brasileiro, que açambarcou desse grupo social o direito de pensar e planejar o futuro ${ }^{3}$. Todavia, as memórias continuam vivas, assim como o desejo de que o Estado reconheça o direito ao território, conforme preconiza a Constituição Brasileira de 1988. O percurso imagético é um pequeno fragmento da riqueza da cultura alimentar do povo da Bocaina. Os objetos, o espaço da cozinha, a agrobiodiversidade, os saberes e sociabilidades, elementos que compõem esse importante patrimônio cultural ${ }^{4}$, são apresentados adiante. Aprecie!

\footnotetext{
${ }^{3}$ Detalhes sobre este processo podem ser vistos em SANTOS e BARROS (2016).

${ }^{4}$ Assumo aqui uma ideia não conclusa de patrimônio cultural, longe da clássica divisão em material e imaterial, mas se aproximando da ideia do conjunto de práticas, saberes, imaginários, expressões e representações que integra a vida das comunidades no presente, na ancestralidade e se projetando, com ressignificações, no futuro, compondo as identidades. Para uma leitura interessante, ver Pelegrini e Funari (2008).
} 


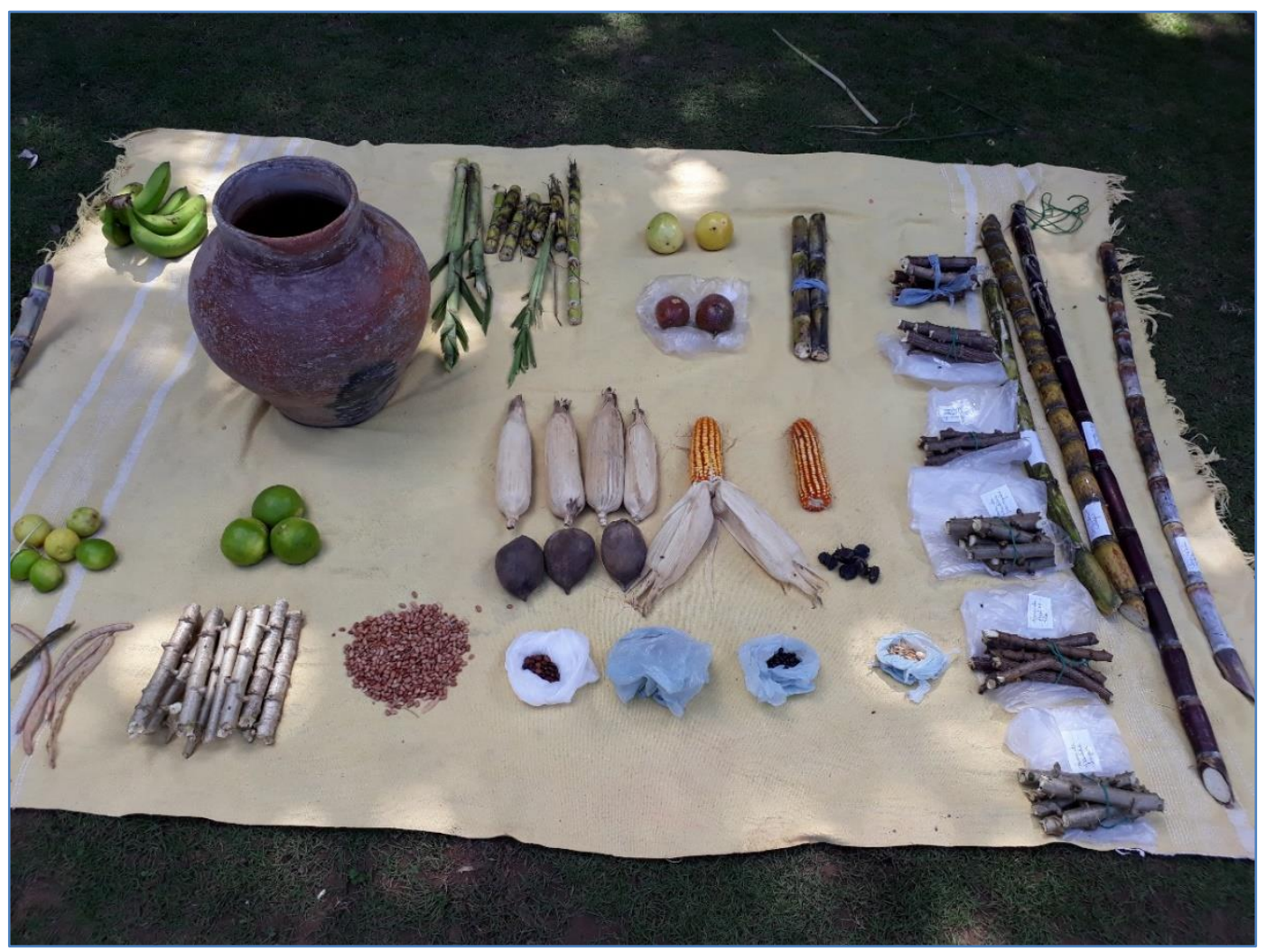

Figura 1: Exposição da agrobiodiversidade quilombola da Bocaina, durante oficina realizada para troca de saberes e sementes entre diferentes famílias. Com o processo de expropriação, muitas variedades foram se perdendo com o tempo e há famílias que já não possuem muitas das sementes que eram cultivadas no passado. Com esta oficina, houve troca das variedades e cada pessoa contou a história das sementes e descreveu suas características, desde o nome até o sabor, textura, modos de plantar, dentre outras. Nesta foto há variedades de feijão, milho, banana, fava, cana-de-açúcar, mandioca, maracujá, limão, dentre outras. As variedades de mandioca registradas, foram: João-do-cerrado, embiruçu, seringueira, liberata, cacau e pão. As variedades de cana-de-açúcar, são: roxinha, caninha-antiga, Maria-pelada e branca. A moringa é um utensílio para acondicionar água de beber. Foto: FBB. Trabalho de campo realizado em abril-maio de 2018.

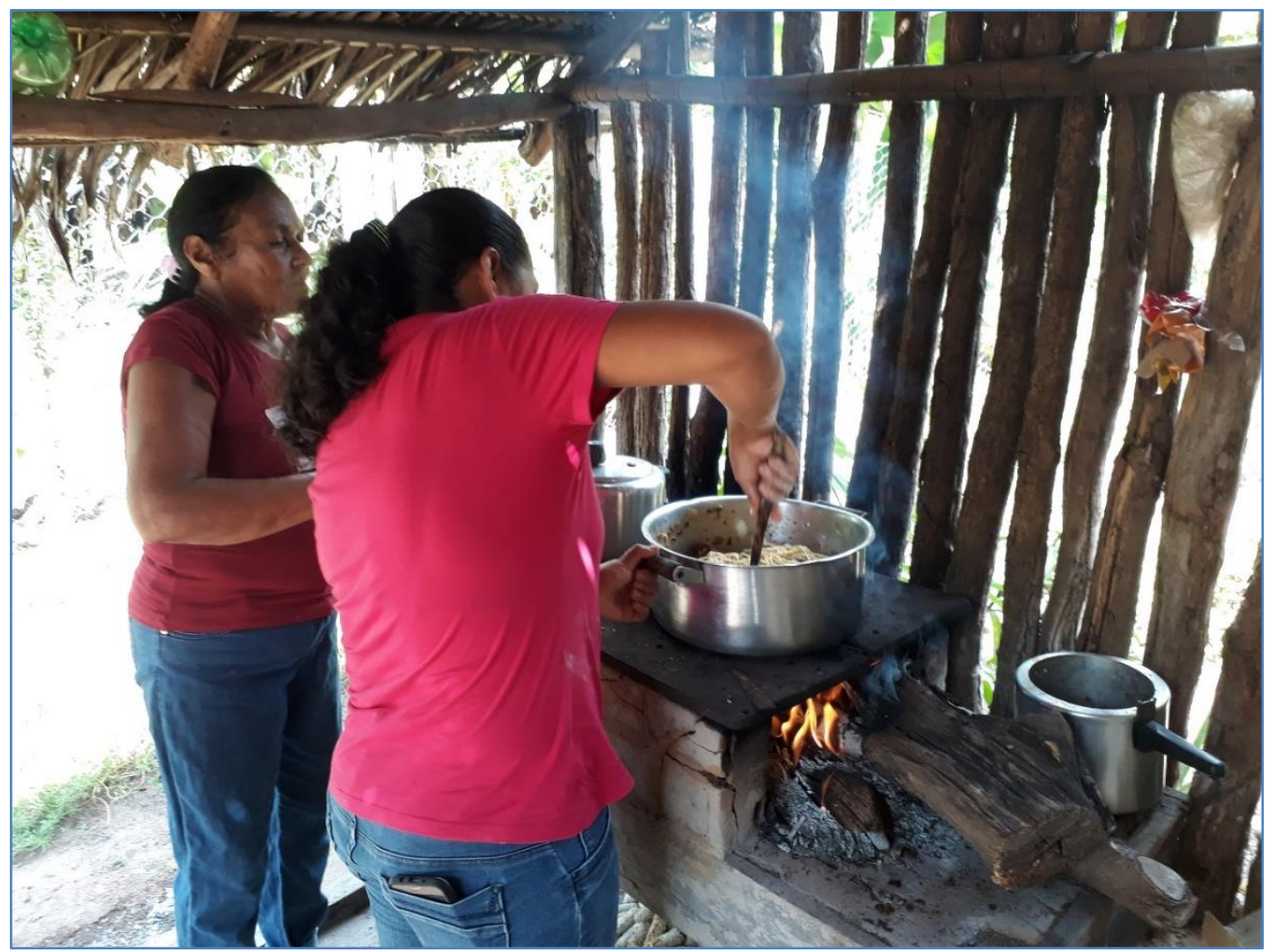

Figura 2: Duas gerações, mãe e filha preparando o almoço dos participantes da oficina realizada no dia 1 de maio de 2018. O fogão a lenha é uma marca importante da cozinha quilombola da Bocaina, podendo ser visto em todas as casas. Geralmente se localiza fora da casa principal. Foto: FBB. Trabalho de campo realizado em abril-maio de 2018. 


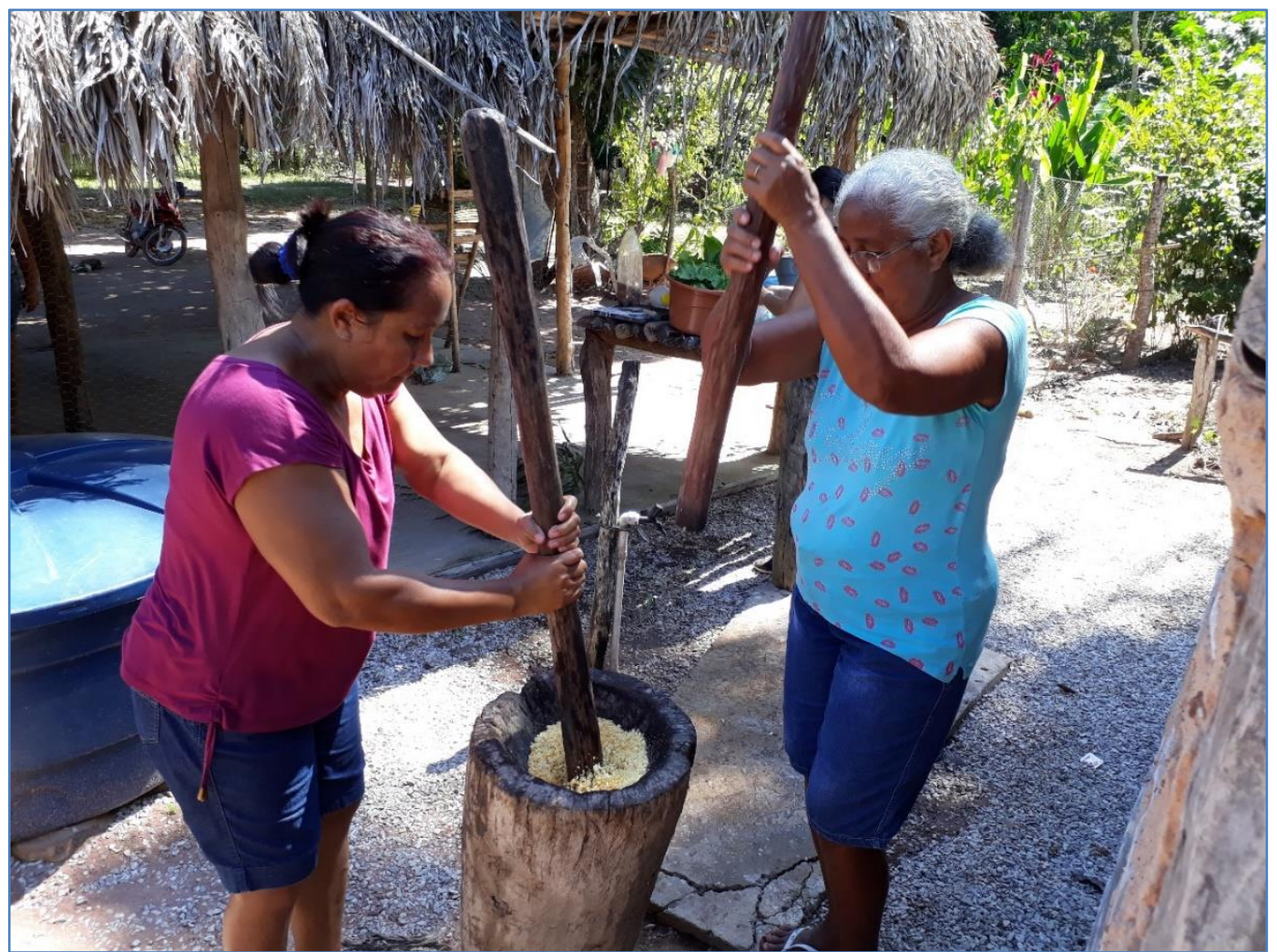

Figura 3: Mãe e filha batendo o milho crioulo no tradicional pilão de madeira para o preparo do biscoito de milho, importante alimento servido, principalmente, nas festas de santo. Foto: FBB. Trabalho de campo realizado em abril-maio de 2018.

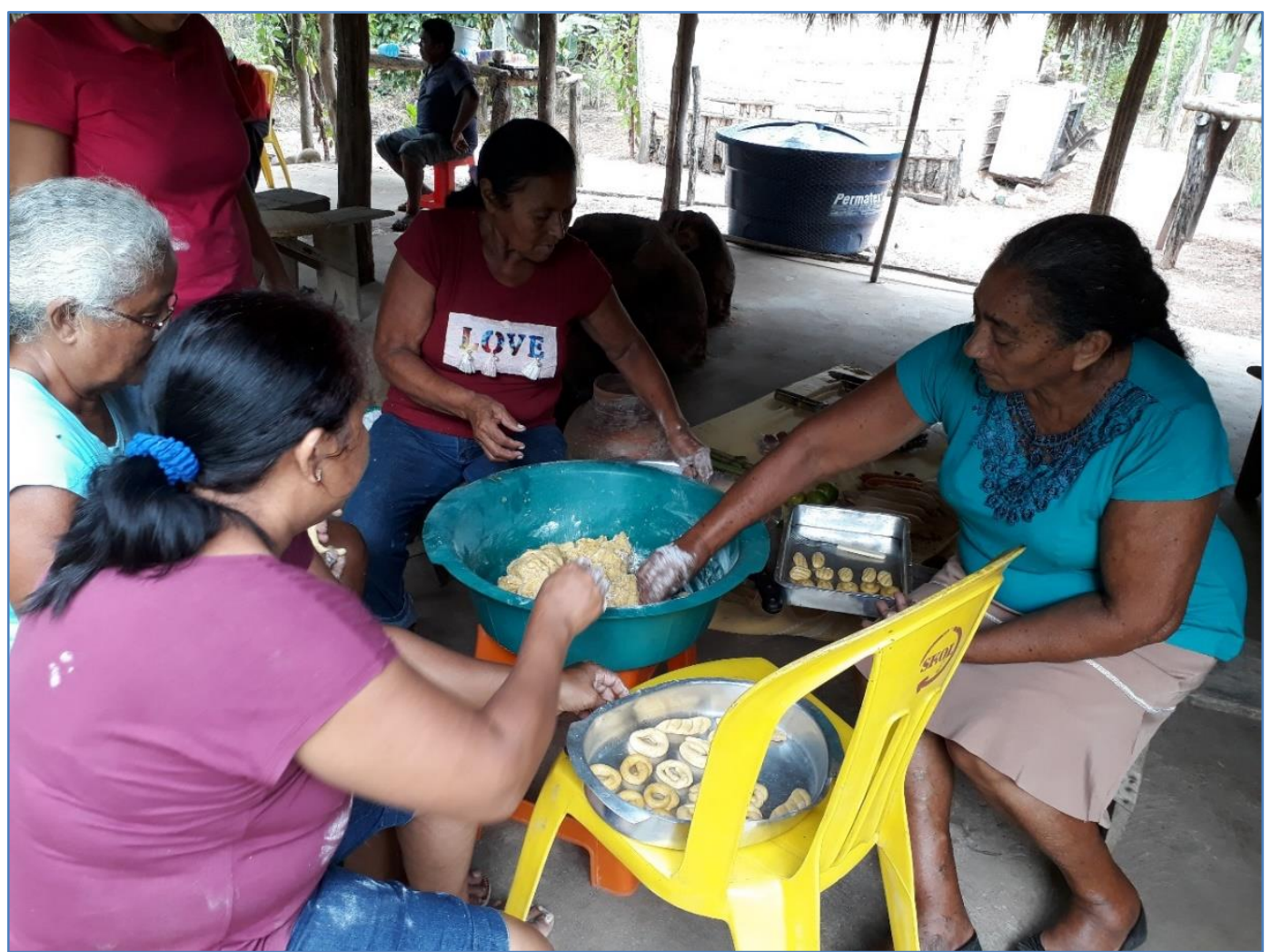

Figura 4: Preparando a massa e enrolando os biscoitos de milho para depois seguirem ao forno. Neste momento de sociabilidade, memórias do tempo da Bocaina foram mobilizadas. Contaram histórias de como as mães e avós preparavam os biscoitos e a importância dos ingredientes originais. Foto: FBB. Trabalho de campo realizado em abril-maio de 2018. 


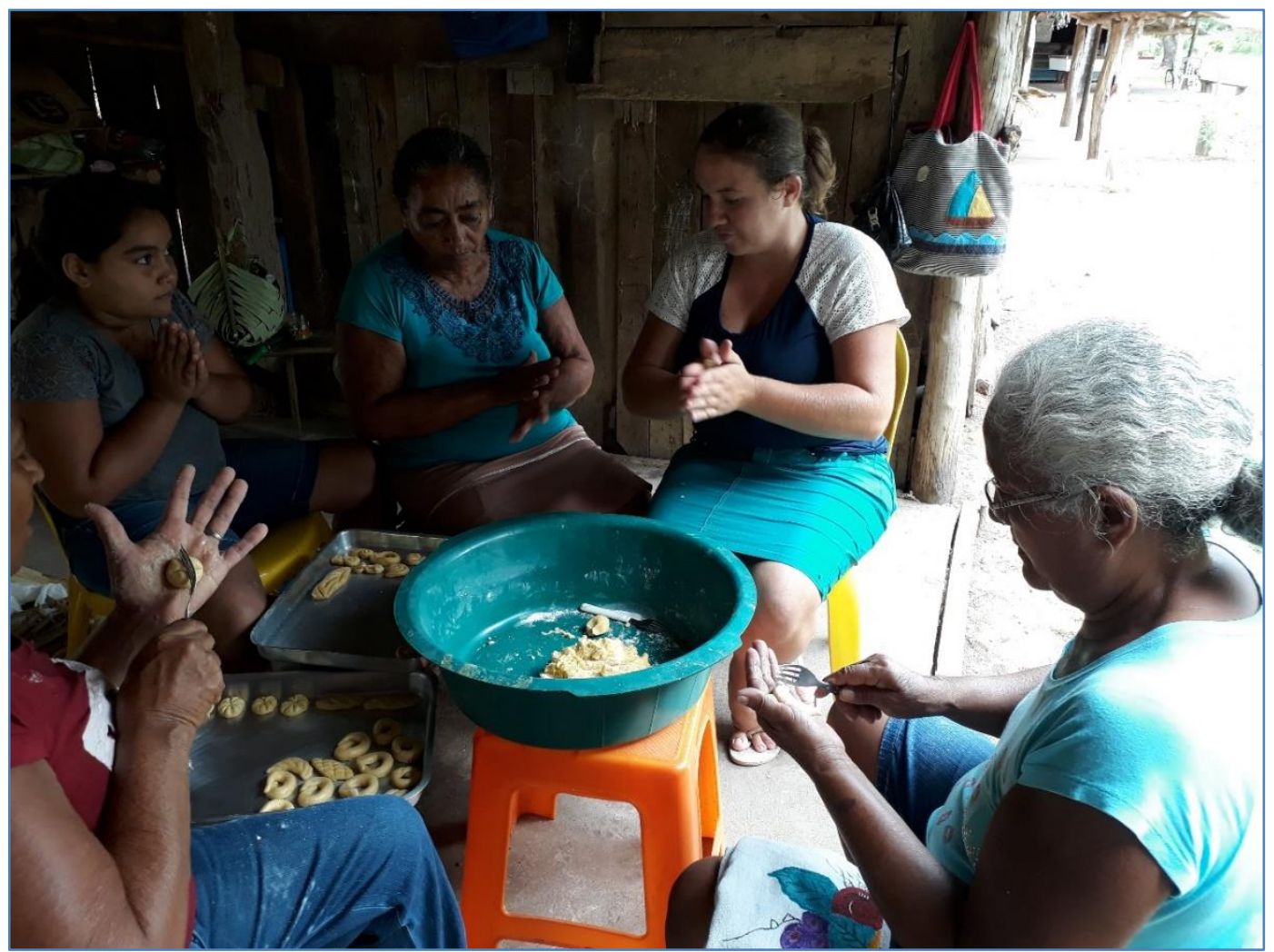

Figura 5: Aprender a fazer biscoito de milho com as experientes. Encontro de gerações no processo de ensino-aprendizagem. Fazer biscoito de milho saboroso implica conhecer as técnicas que vão desde escolher bons milhos, pilar de maneira adequada, preparar bem a massa, fazer os bolinhos em diferentes formatos e riscar, até controlar o tempo no forno para que não fiquem crus ou assados demais. Foto: FBB. Trabalho de campo realizado em abril-maio de 2018.

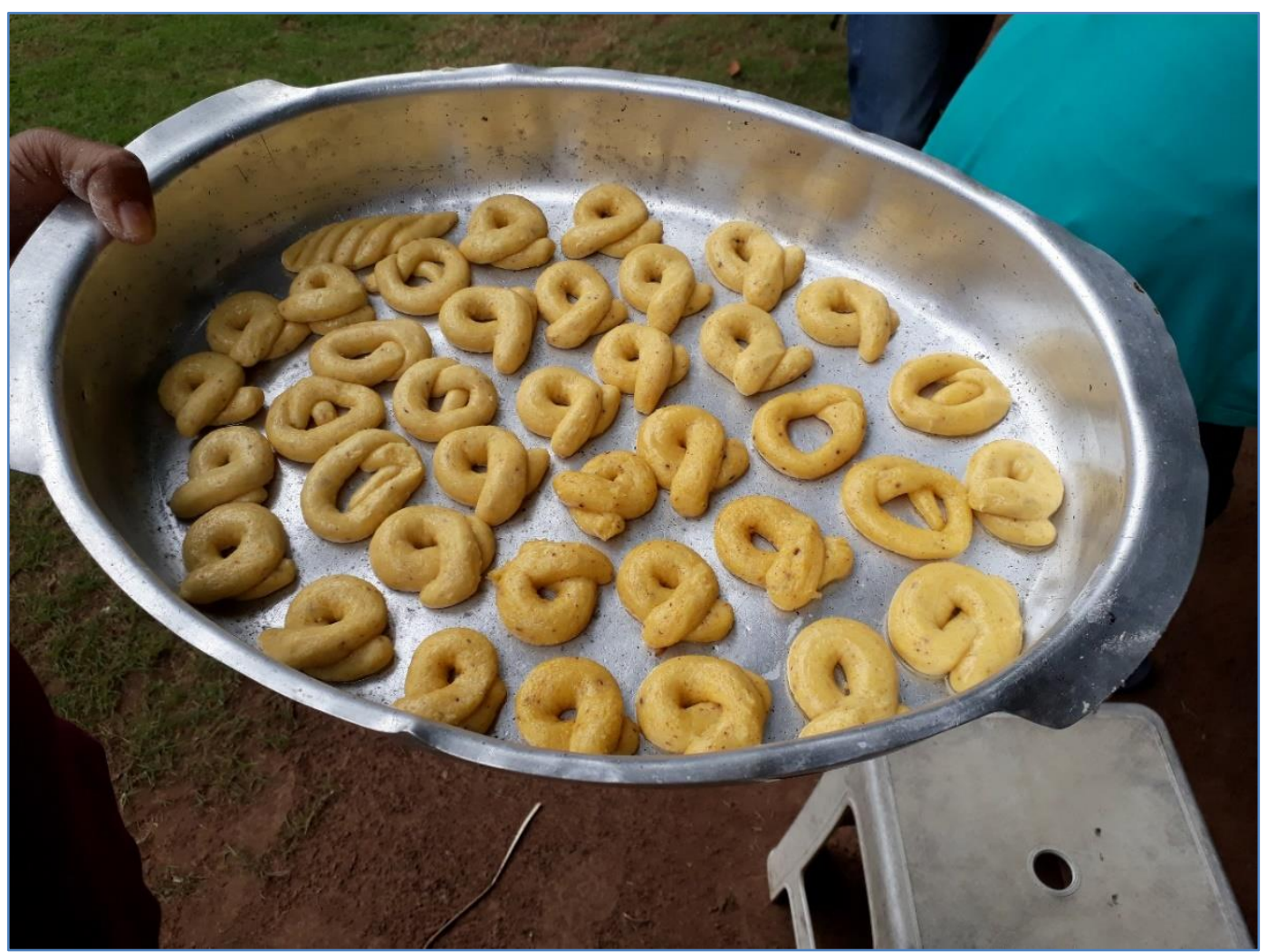

Figura 6: Biscoitos de milho prontos para ir ao forno. Foto: FBB. Trabalho de campo realizado em abril-maio de 2018. 


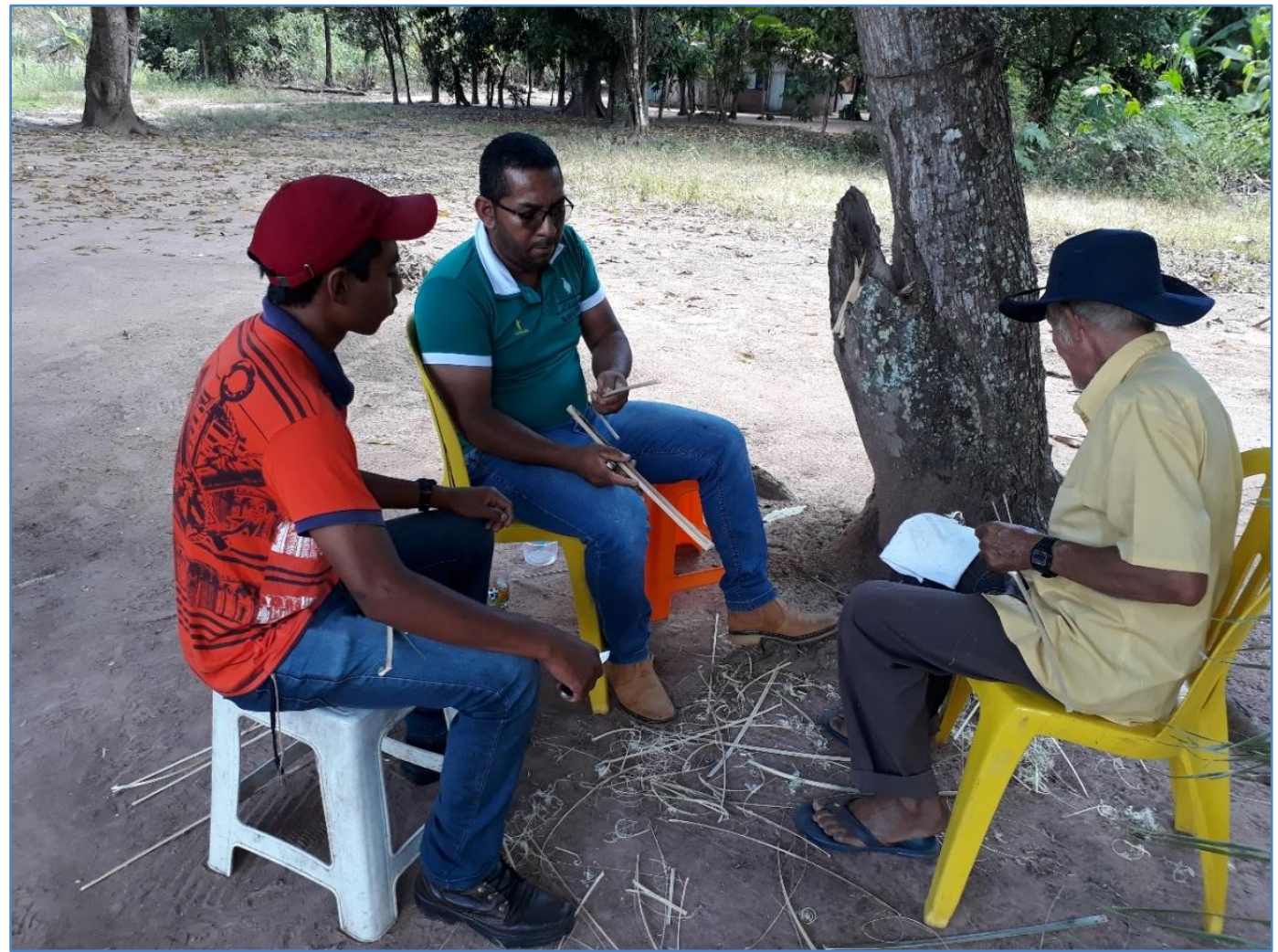

Figura 7: Os homens, de diferentes gerações, ensinando e aprendendo a manusear as fibras vegetais que serão usadas na elaboração da apá. Foto: FBB. Trabalho de campo realizado em abril-maio de 2018.

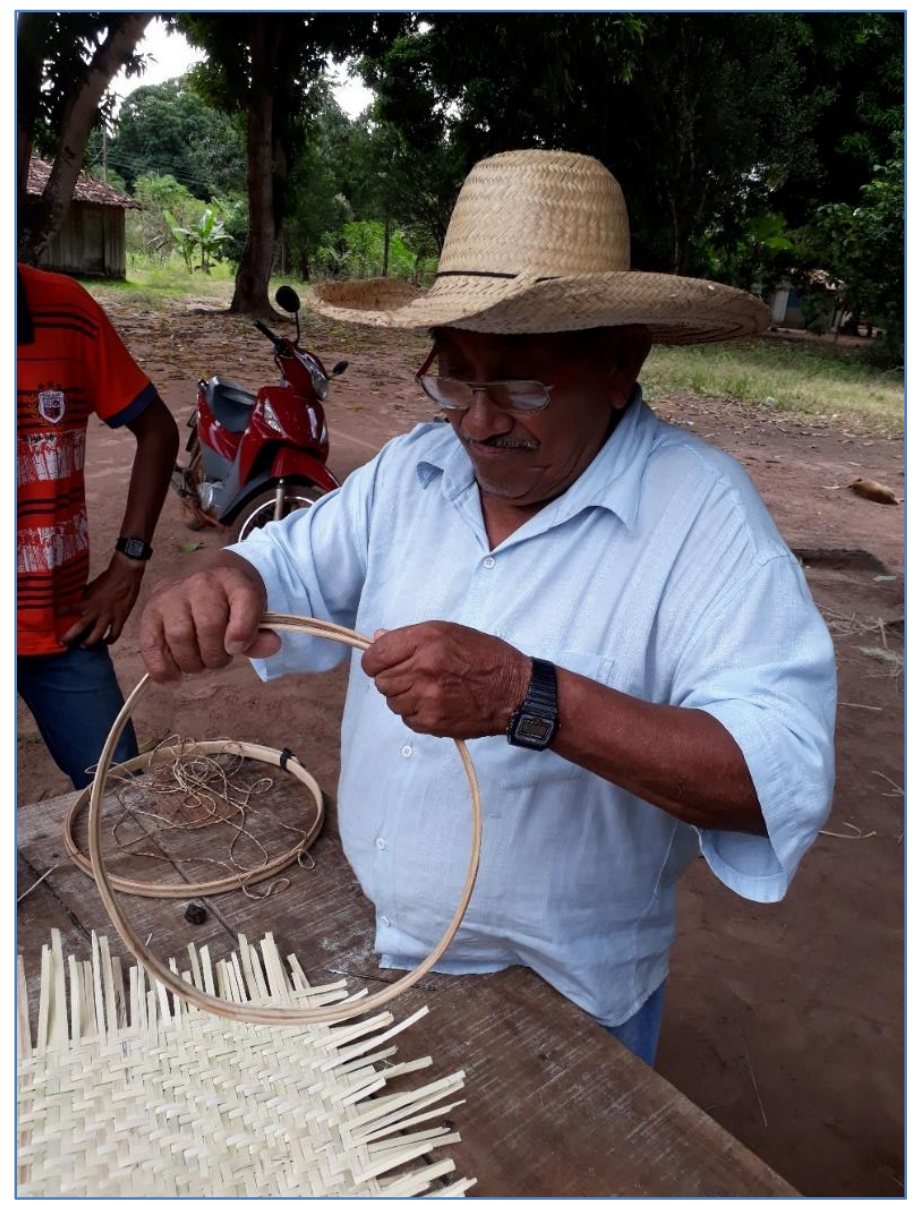

Figura 8: Seu Júlio ensinando aos comunitários como elaborar uma apá, utensílio doméstico usado para catar grãos, como milho, arroz e feijão. É feito com fibras vegetais de taboca (bambu) e cipó e amarradas com barbante de algodão. Foto: FBB. Trabalho de campo realizado em abril-maio/2018. 
Barros. Cultivar, compartilhar e comer: fragmentos da cultura alimentar quilombola da Bocaina (Mato Grosso). Ethnoscientia 5, 2020. DOI: D.O.I.:

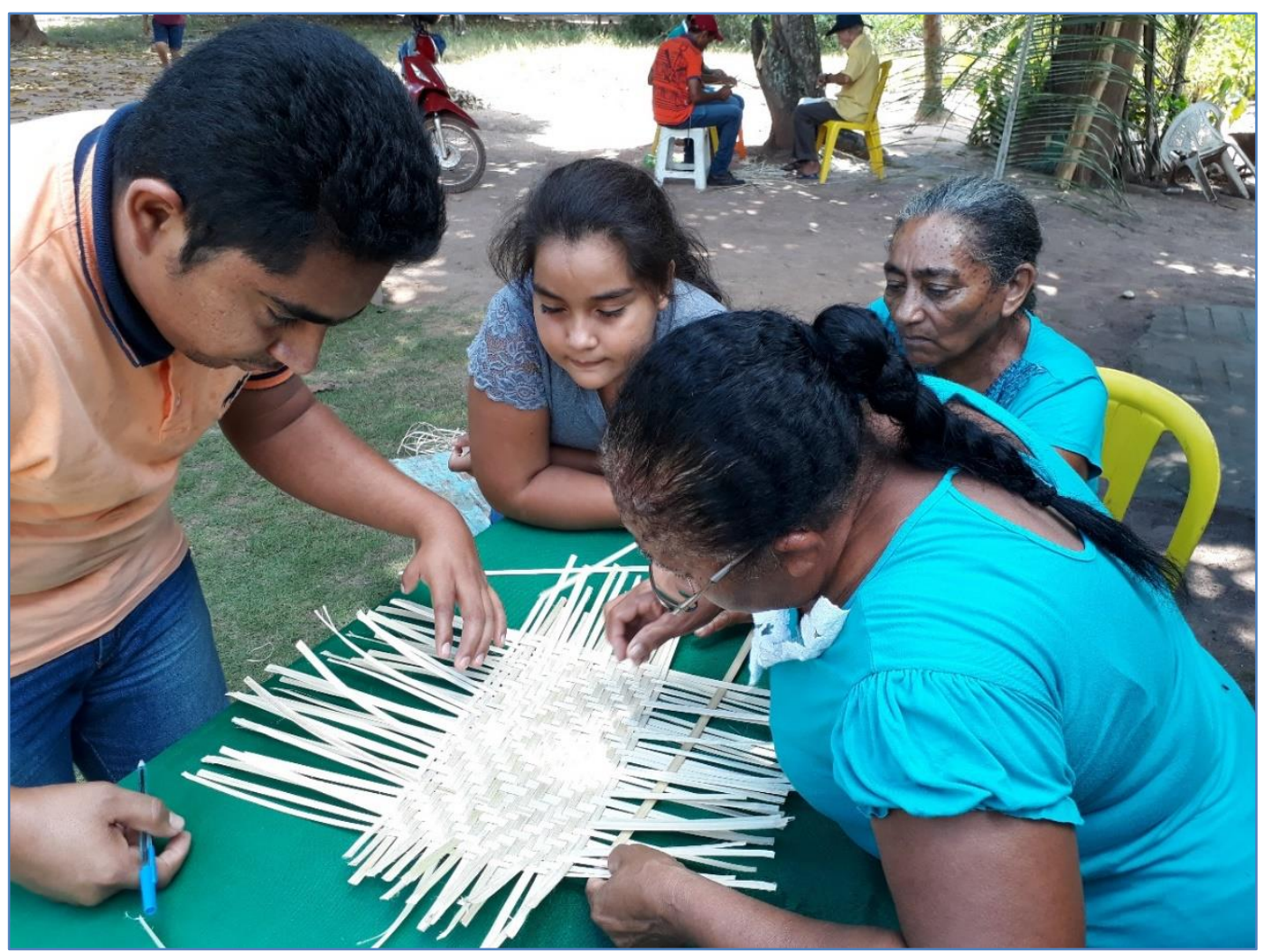

Figura 9: Montando a base da apá. Técnica, observação e concentração roubam a cena. Foto: FBB. Trabalho de campo realizado em abril-maio de 2018.

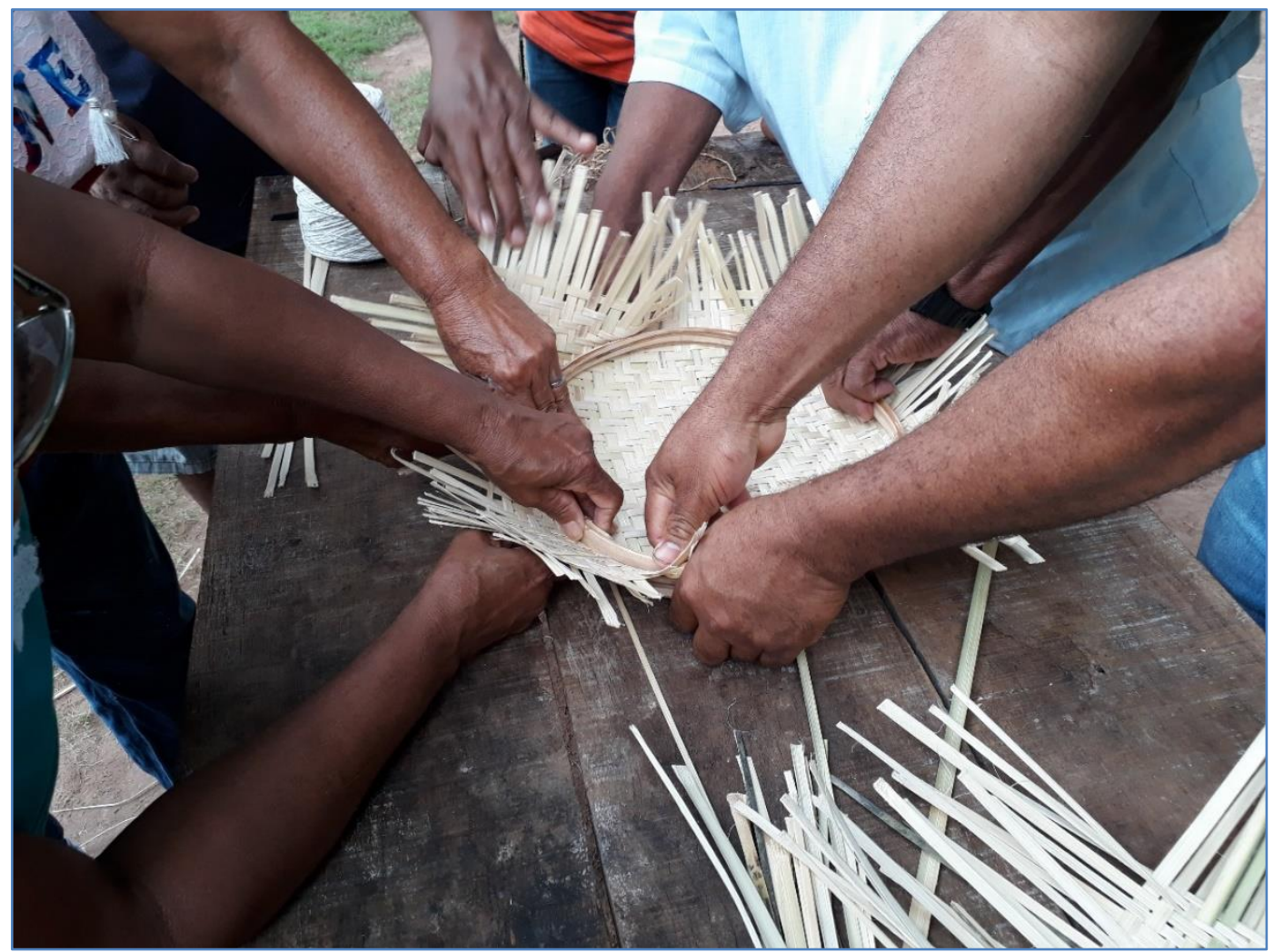

Figura 10: Mãos à obra. Todas e todos juntos tecendo uma apá sob as orientações de Seu Júlio, um dos poucos fazedores de apá na comunidade. Foto: FBB. Trabalho de campo realizado em abril-maio/2018. 


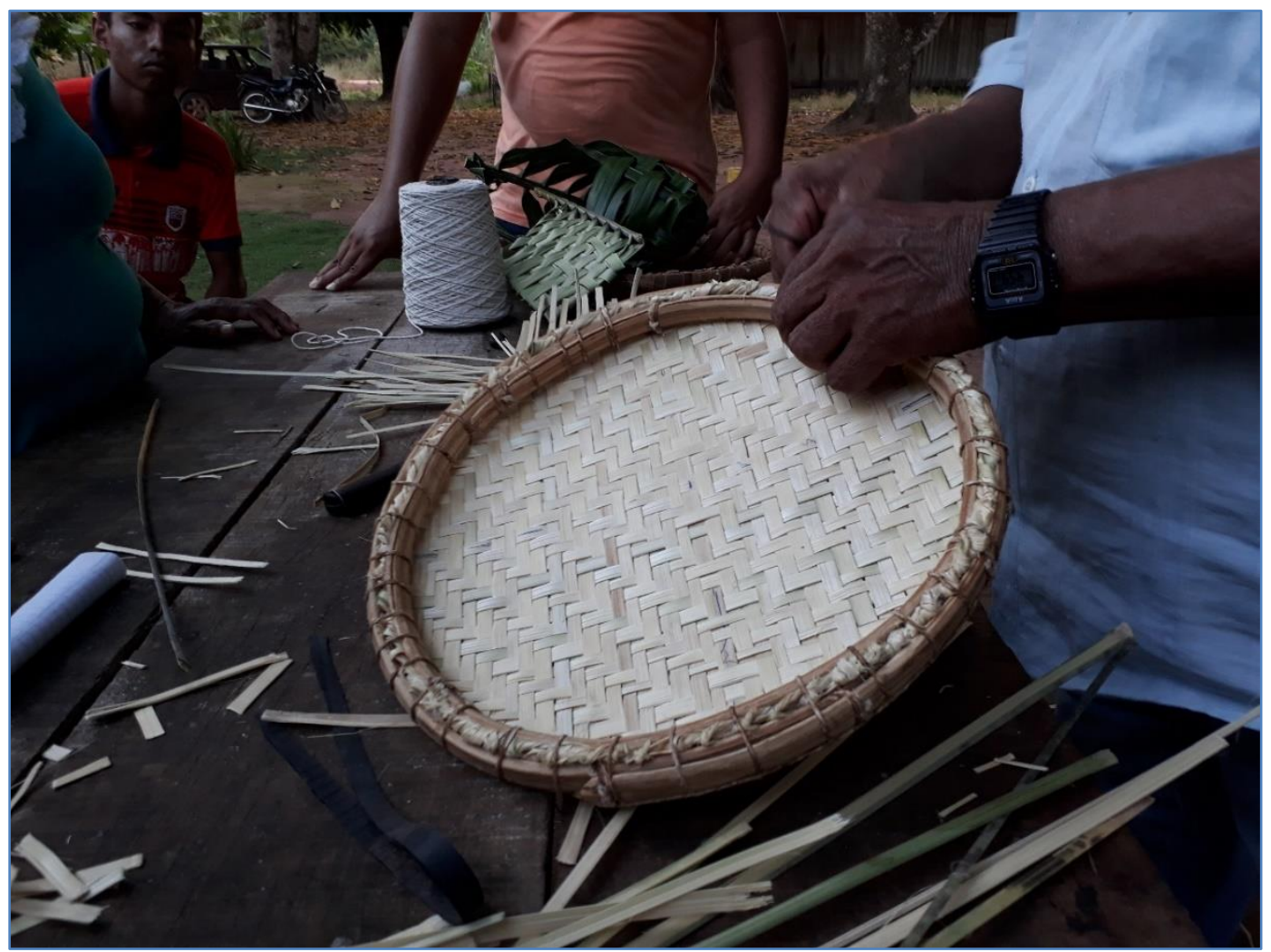

Figura 11: A apá pronta. Hoje, novos membros da comunidade sabem fazer este utensílio doméstico. Foto: FBB. Trabalho de campo realizado em abril-maio de 2018.

\section{REFERÊNCIAS}

DAMATTA, Roberto. O que faz o Brasil, Brasil? Rio de Janeiro: Rocco, 1986.

ECKERT, C.; DA ROCHA, A. L. C. Etnografia: saberes e práticas. Iluminuras, v. 9, n. 21, 2008.

MACIEL, M. E. Olhares antropológicos sobre a alimentação Identidade cultural e alimentação. In: CANESQUI, A.M.; GARCIA, RWD. (Orgs.). Antropologia e nutrição: um diálogo possível. Rio de Janeiro: Editora FIOCRUZ, 2005.

MENASCHE, R. (Org.). Saberes e sabores da colônia: alimentação e cultura como abordagem para o estudo do rural. Porto Alegre: Editora da UFRGS, 2015.

PELEGRINI, S. C. A.; FUNARI, P. P. O que é patrimônio cultural imaterial. São Paulo: Editora Brasiliense, 2008.

SANTOS, T. A. C.; BARROS, F. B. 2016. O povo está esparramado...”: o processo de desterritorialização vivenciado pelos quilombolas da Bocaina, Mato Grosso. Estudos Sociedade e Agricultura, 24(1), 209-242, 2016.

THIOLLENT, Michel. Metodologia da pesquisa-ação. São Paulo: Cortez Editora, 136p. 2005. 